\title{
Rising Tendency of Journalism Practised on Social Media Sites
}

\author{
Jan-e-Alam Solangi* \\ Department of Media \& Communication Studies, University of Sindh, Jamshoro, \\ Sindh, Pakistan
}

\section{Article Type: Article \\ Article Citation: Jan-e-Alam Solangi. Rising tendency of journalism practised on social media sites. Indian Journal of Science and Technology. 2020; 13(01),51-60.D0l: 10.17485/ijst/2020/ v013i01/148456}

Received date: 0 ctober 27, 2019

Accepted date: November 15, 2019

*Author for correspondence: Jane-Alam Solangi $\mathbf{V}$ alam.solangi@ usindh.edu.pk $\odot$ Department of Media \& Communication Studies, University of Sindh, Jamshoro, Sindh, Pakistan

\begin{abstract}
Objectives: The motive of this research study is to evaluate the influence and attractiveness of Social Networking Sites (SNSs) in the amidst the full time working journalists and the part time media practitioners, located in Hyderabad and Karachi practicing on SNSs in their professional field of work. This study examines individual approach, comfort ability, usefulness, and inclination towards the most popular SNSs. Method: The statistics of this research work were congregated through Web-based Questionnaire Survey. That was dispended among the journalists of Hyderabad and Karachi region in Sindh Province, Pakistan. The data were collected through an online Google Docs form out of 386,309; valid questioners were selected for this research and evaluated in SPSS Software. This research work has focused on acceptance of the Technology Acceptance Model (TAM) proposed by Davis (1986) for diversified description of information system and communication technologies. This research examines individual inclination towards Social Media in a Media Profession. Findings: The pronouncement has been shown in Tables and then illustrated and interpreted to perceive the SNSs e.g. Facebook, Twitter, Instagram, Whatsapp, etc. and their acceptance and adoption by full time journalists and part time media practitioners. In this approach, it was recognized that the journalists have a great inclination towards SNSs which enables them to exchange information promptly with ease and confidently practice in the field of journalism. Novelty: In the era of technology, SNSs like; facebook, Instagram, Bebo, Twitter, and Whatsapp are widely used by professional journalists as well as active citizens for journalistic purposes which highlight the untold stories.
\end{abstract}

Keywords: Social Network Sites, TAM, Facebook, Twitter, Whatsapp, Journalists. 


\section{Introduction}

Social Networking Sites (SNSs) viz. Facebook, Instagram, My Space, Twitter, etc. have opened up a new vista of world and have provided a vast as well as more democratic platform to share the certain pertinent social, political, economical, cultural, and religious values without any fear of discriminatory or partisan censorship. The platform provided is fully impartial and entirely non-partisan that welcomes cordially even the harshest dissenting voices.

The Sites differ in their features and accept the data which fall under the capacity and range of their nature. For example, twitter is a micro blog and can support to carry only 144 characters. Researchers in this regard have harnessed their focus on determining the practices, suggestions, and cultures with respect to the above mentioned sites. Moreover, keeping in view the usage of such sites, researcher will probably try to comprehend the acceptance of these sites in Pakistan's context.

The very purpose of this research is to put forward a practical, applied, and recorded intelligibility of the business involved. Here the purpose is to underscore what man oeuvre the concerned sites and their futuristic development after some point of time. After the detailed theory of evolution and customers' intentions to use the Technology is discussed. We surveyed people of TAM (Technology Acceptance Model) and people's actual use of SNSs we culminated with a depiction of the articles incorporated into this uncommon area and recommendations for upcoming research.

Facebook adopts an alternate strategy to either allow or disallow the friends, fans, and followers to know one's short bio-data via profile. It is a peculiar property of nearly all the SNSs to restrict the access to personal information or to expand it at a large scale. Being a member of SNSs, you distinguish between the users with respect to the site they surf on. Coming to those in touch with us are can be divided into three categories of Friends, Contacts, and followers. Friends' category demands for mutual consent to come in terms, whereas the latter two categories are bound by one-directional access without the approval of the other side that the relationship is sought. Such unidirectional ties are branded as "Fans" or "Followers" but some sites consider Fans or Followers as Friends. Their very consideration is not substantial in genuine vernacular terms due to weird sense of one sidedness [1]. Social sites provide an access and facility to post any material on friend's wall. Different suitable levels are used for leaving comments and sometimes bound by some security too, which hinders the posting on a friend's wall. Birthday wishes or nearby events offer the best example in present context. Private messaging is another ingredient in the delicacy.

Keeping in view what has been observed above, the sites differ in their nature, like some are limited to only pictures sharing; the others give a vast platform for sharing videos while the rest are suitable for text messages sharing. Likewise, versatile SNSs are available (e.g., WhatsApp) and some other are comparatively more convenient for interchanging: Facebook, Twitter, and Instagram.

Mainly, the sites are aimed at targeting the users on the basis of topography and demography though it does not perfectly decide the site's supporters. English-oriented site "Orkut" was launched by the USA but was dominated by Portuguese-speaking Brazilian 
[2]. Yes, a few sites can be judged with regard to their propensity towards ethnicity, religion, race, and political tendency. There are even the sites dealing with cattle, like Catester and Dogster that are dealt with by their breeders.

\subsection{Statement of the Problem}

The indispensible extensive change that Social Media Sites have brought to the field of mass communication and journalism, that Social Media set-up have empowered all sort of users to accumulate and impart News Information promptly across the globe. Social Media has the capability to redefine the concept of journalism from traditional one-way asymmetric model to collect or participatory system [3], however, they potential benefits of Social Media/Networking Sites cannot be fully realized until these systems are not effectively utilized by the intend users (i.e. journalists).

Therefore, it is crucial to identify and investigate the factors that influence Social Media Systems Acceptance and usage in order to increase their acceptability and usage.

Previously, no research has been carried out in Pakistan on Social Media Sites usage and Acceptance model, in lacking prior research on ease of use and perceived usefulness of Social Media Sites among journalist in Hyderabad and Karachi. This research work is starting point from which explore the types of SNSs acceptance and reliability on its usage by journalists.

\subsection{Aims Objectives}

To identify and explore the important factors that affect SNSs acceptance usage from extant literature.

To develop a Theoretical Model incorporates constructs from two stream of research, i.e. Media richness theory and technology acceptance.

To provide recommendations for academicians and media practitioners.

\section{Literature Survey}

SNSs have ushered in an ocean of users under the umbrella of digital sites, like Facebook, Twitter, and Myspace. These destinations rely upon developing relationship or support from that already in contact or from gathering of companions with similar or shared interests [4] characterize an informal organization as an "unequivocal portrayal of the connection amongst people and gatherings in the groups".

At another place [5], reveals that unusual groups share the stage where the people of identical thinking gather, confer, share, and discuss their ideas into the best possible potential depth. From promoting correspondents' viewpoints, widely-known social sites, like Facebook and Bebo activate system of checks for their security and provide huge access to information shared. SNSs also frame a platform for the promoters keep close regard in case of any alteration.

In any case, it is thought that a reasonable arrangement of an activity to the extent of using SNSs continues dodging sponsors. The casual association profile is the joining of 
one's relational communication presence. Each profile page is peculiar to the user and grants other onlookers to genuinely "sort oneself into being" [6]. Every bit is provoked to show their own profile with personal DP and share a chunk of an individual information, for example, what class they attended or which motion picture they like and love the most including music [7]. Social Networking is substantial platform for exchanging issue of interest, and for all you know contact or reviving connection with other users effectively .as claimed by [8] 55\% of recruit befall a Social Media Sites no less than once a week. Social Media interpret as a classification of internet based use that set up doctrine and automation support of web2.0 and permit the formulation and interchange of customer developed content" [9].

\section{Facebook}

Such open services sites have bracket themselves into demographic segmentation keeping in view the growing number of users. Apart from the past SNSs, Facebook was intended to associate to a particular CAN (Campus Area Network) networks. Coming into being in mid 2004 at the hand of Harvard pass out guy [10]. In beginning, it was restricted to only those who were part of Harvard and possessed harvard.edu email. But then after, it stepped onto a vast canvass of SNS that ended up connecting the entire world. Its use extended much more than what it designer had expected.

It was opened to general public but still requires the approval of authority. Without genuine email, there persists the shadow of doubt that whether the data are secure or vulnerable to possible leakage (As of this written work, just enrolment in local systems requires no authorization). Features that make Facebook distinct is its capacity to develop or assemble "applications" which enable users to alter and make changes in their profile at their will and perform the given assignments, for example, diagram travel histories or world heritage sites.

While most of the SNSs concentrate on developing extensively and exponentially, others unequivocally look for small group of users. A very few and small number of users have confined themselves within a limited and specific access to world class social sites. Many other sites, like Couch surfing, My Church, and Black planet divide their users demographically. In the end, any individual who wishes to make specialty SNS can do so easily on Ning, a stage or platform that facilitate users to develop SNS of their own vesting the authority and power of approval in their own hand.

\section{Twitter}

Micro blogging is comparatively smaller means of communication in social cyberspace and it is delivered to associates of the network. It is also known as tweets in common and everyday language. Tweets that are short posts could be included into our vocabulary same as Xerox for its copying machine and Google as search engine. For our research study, we will be directing towards the phenomenon as micro blogging. Micro blogging specifically 
impacts eWOM correspondence since it permits individual exchange such influencing considerations, that is, Slant or anyplace: while driving, sitting at any restaurant, working at an office or at home; to nearly anybody "connected", that is, Web, IM, mobile phone, or email on such a high scale that had not been ever found previously. Its peculiar brevity and smaller scale has reduced the users' headache of composing long contemplations. It is definitely miniaturized scale part that makes miniaturized scale sites extraordinary as compare to other eWOM media which include long textual pages and WebPages. Its standardized version is around the size not exceeding 144 characters or equal to a commonplace daily paper feature and subhead [11]. It eases and further simplifies it to both create and expand. Though the message is non-concurrent but targeted, aimed at whom to read and refreshes. They are saved and can be searched via site's indices without any trouble or time-taking. Since they are on web, they are additionally and normally open by anybody with an internet association. To put it plainly, these miniaturized scale marking remarks are prompt, omnipresent, and adaptable. For eWOM, these miniaturized scale online journals offer prompt notion and give understanding in full of feeling responses towards items at basic interactions of the basic leadership and obtaining proceedings. The present review is aimed at analyses the small scale site dispositions having larger canvass by means of prevailing postings.

\section{WhatsApp}

The application traces its origin back in 2009 and practically came into operation in 2010 . Its advent coincided nearly with the emergence of Smartphone which provided lifeline to it. It is actually the substitution of SMS which carried only text. WhatsApp brought with it several other features too: audio, video, and photos. Its operation is free of charge but online data is somewhat consumed that's too in bits not in MBs. In last two years, many more other features have also been introduced to entertain the user, WhatsApp status, etc. [12] as claimed by a researcher one out of seven individual are using what's app across the globe" accordingly what's app" these days pre owned as a media device. What is more surprising is that it has drawn nearly 400 million users in past two years due to which it can be branded as vast and worldwide connecting Social site. Moreover [13,14], in stream position Whatsapp has curtailed the obstacle between the journalist and the source. The platform is totally ad-free which has added much grace to it.

\section{Social Networking Sites Usage}

There has been noteworthy improvement of long-range informal communication destinations (SNS, for instance, Facebook, LinkedIn, My space, and Instagram). While the use SNSs has affected individuals' regular day-to-day existences. They have, moreover, gotten the thought of partnerships since they make business for both electronic business and ordinary associations. 
SNSs, all alone, can be beneficial business parties, producing incomes for their associates and shareholders as showed by achievements of Facebook, LinkedIn, and My space... Other online business associations can, clearly, fuse SNSs instruments and attributes into their present web applications to enhance or hold their use in basic applications. Also, SNSs users can give new opportunities to regular organizations to streamline their essential operations and redesign their cooperation with clients, associates and suppliers... In spite of varieties in how their business operations are done. SNSs can just win having clients, delegates and accomplices utilize them. This is because of the way that as group was development. SNSs rely upon the associations between their clients and thus their regard increment as the clients' systems broaden.

Along these lines, it is critical to comprehend client's conduct (why individuals use SNSs) and use designs inside SNSs. Be that as it may, to date, few reviews have been methodically inspected that what determinants add to SNSs usage.

\section{Research Method}

A survey method (design) was chosen for this research study. Field survey approach based on questionnaire method was used to identify the characteristics of a population, behavior, attitudes, necessities, and values through surveys. Hypotheses testing are often used to draw rational conclusions. The quantitative research approach helps to make interpretations based on statistical in order to collect the sample total 386 individuals participated in the study. 150 questionnaires were collected through online system Google Docs Forms. Out of 386, 309 valid questionnaires were selected. Random Sampling method was selected for this research. This method can help to achieve the sample that is a precise representation of a larger population. The data were analyzed by using SPSS software.

\section{Result and Discussion}

The results are also represented in Demographic Profile (Table 1).

TABLE 1. Demographic profile

\begin{tabular}{lll}
\hline Variable & Frequency & Percentage \\
\hline Gender & \multicolumn{2}{|}{} \\
Male & 180 & 58.25 \\
Female & 129 & 41.75 \\
\hline Age & \multicolumn{2}{|}{} \\
\hline $18-25$ & 111 & 35.92 \\
$26-33$ & 107 & 34.63 \\
$34-41$ & 66 & 21.36 \\
$42-49$ & 17 & 5.50 \\
$50-60$ & 7 & 2.27 \\
\hline Education & & \\
Bachelor & 140 & 45.31 \\
Intermediate & 45 & 14.56
\end{tabular}




\begin{tabular}{lcl} 
Masters & 107 & 34.63 \\
$\begin{array}{l}\text { Matriculation } \\
\text { Others }\end{array}$ & 2 & 0.65 \\
\hline Monthly income & 15 & 4.85 \\
Below Rs. 30,000 & & \\
Rs. 30,000 to Rs. 50,000 & 50 & 6.15 \\
Rs. 50,001 to Rs. 70,000 & 71 & 16.18 \\
Rs. 70,001 to Rs. 90,000 & 79 & 22.98 \\
Rs. 90,001 or above & 90 & 25.57 \\
\hline Number of Facebook users & 29.13 \\
0-10 & 19 & \\
11-25 & 50 & 6.15 \\
26-50 & 71 & 16.18 \\
51-100 & 79 & 22.98 \\
Above 100 & 90 & 25.57 \\
Frequency of using Facebook & 29.13 \\
Less than an hour/eek & 19 & \\
Less than 5 h/week & 50 & 6.15 \\
About 10 h/week & 71 & 16.18 \\
About 15 h/week & 79 & 22.98 \\
More than 15 h/week & 90 & 29.57 \\
\hline
\end{tabular}

\subsection{Principle Component Analysis}

To test the model suitability, the 'Kaiser-Meyer-Olkin Measure of Sampling Adequacy', from here on referred to as KMO, and 'Bartlett's Test of Sphericity' is used. Following the general rule of thumb, the model at hand is considered a significant fit as the value of KMO statistic is above the required threshold of 0.70 , while the generated significance value is 0.00 , less than that of 0.05 sufficing the Bartlett's test as well.

\subsection{Rotated Component Matrix}

The Rotated component Matrix which is shown in Table 2 to show that factors are relevant and belong to their own constructs, and help measure the results while not affecting or accounting to any calculations of any other construct. The factors are obtained on varimax rotation principle. The basic rule used for concluding extrapolations from this method is as recommended by signifying that the values for each of the factors should be above 0.40 for it to be proven consistent and reliable. Cross loadings in the case were ignored as the loadings of the factors mentioned below had difference of more than 0.20 . In addition, the loadings for all the below mentioned indicators are above 0.70 demonstrating that the indicators are adequately reliable to carry out the analysis for empirical evidence.

It is important to mention that the values of model fit were concluded after the removal of one item loading (Indicator) from the model subsequent the pilot study, which was conducted on a group of students from university, the item was from the. The indicator was removed from the model for one or more reasons; the item or indicator had a value 
TABLE 2. AVE test/convergent validity

\begin{tabular}{llll}
\hline Variable & No. of items & AVE & Composite reliability \\
Perceived ease of use & 5 & .69 & .91 \\
Perceived usefulness & 5 & .72 & .93 \\
Critical mass & 3 & .84 & .94 \\
Capability & 3 & .54 & .78 \\
Perceived Playfulness & 4 & .72 & .91 \\
Trustworthiness & 4 & .85 & .96 \\
Intention to use & 3 & .82 & .93 \\
Actual use & 2 & .82 & .90 \\
\hline
\end{tabular}

of less than 0 , which could be due to a few reasons. The question that was asked by the respondent might have had vague language or complicated wording which confused the respondent. The item value of below 0.4 must be removed as it interprets that that indicator does not support or advocate the construct in case. The indices stated acceptable fits after elimination of that indicator and the total of 10 indicators are were included in the study instead of initial 11. The factor loadings from CFA are portrayed. As expressed, the values of each of the indicator is above 0.40 , however, the indicator CP5 showed value below 0.40 , but is kept in the model as the exclusion of the indicator caused the Root Mean Error of Approximation (RMSEA) to increase above the value of 0.05 and decrease for other fit indices. The results are expressed as follows.

\subsection{Partial Least Squares-Structural Equation Modeling}

\subsubsection{Model Evaluation: Reliability and Validity}

Above Figure 1 elaborates the conceptual framework adopted in the study making EU, $\mathrm{CM}, \mathrm{CP}$, and PP are all independent variables for the perceived usefulness. While intention to use depends upon perceived usefulness and trustworthiness of the SNSs which in turn have effect on the actual use of the technology of SNSs?

It has also been mentioned that the values of C.R are greater than the values of AVE of the in study constructs, the data can be proven to be valid and be used for the research purposes. Therefore, the validity measures to evaluate the constructs conducted to analyze the C.R are greater than AVE. To check the further validity of the constructs incorporated in the study, convergent validity results are demonstrated in Table 2. As the rule of thumb, the values of AVE should be equal to or greater than 0.50. As evident from Table 2, all the values extracted for AVE using Smart PLS 2 are less than that of C.R, hence the reliability

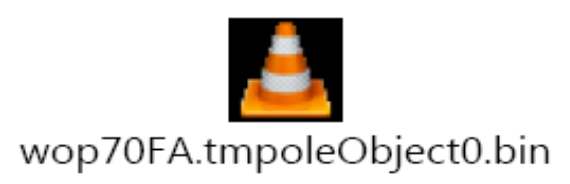

FIGURE 1. Algorithm test run on PLS-SEM. 
of all constructs demonstrate to be acceptable for the research purposes. With the test being done and the values of C.R above the AVE values, the conclusion can be made that the items and the constructs in the study have convergent validity

\section{Conclusion}

The information discovered that pragmatic intention of perceived usefulness of Social Media Sites are crucial and definitive elements of users' intention of using the Social Media which is spiral and beacon of actual usage, demeanor of Social Network Sites on the substructure of TAM, to explore and provide information about the behavior of SNS links by means of Social Media such as, Facebook, Twitter, Instagram, and Blogs. Researchers have further examined and combined the supplementary constructs; Cm Social Media CPs and PP produce the TAM.

More studiously in the comprehension of acceptance model and usage of Social Media, nonetheless ongoing course is meant to find the obstructions that need to be identified first. Since the analysis was conducted from working journalists of Hyderabad and Karachi for being both the metropolitan cities in Sindh which are the hub of national as well as international journalists, and the research during survey revealed that the journalists who partake in survey accepted to enthusiastically using the SNSs which exemplifies insignificant portion of journalist who use social media in millions the worldwide for the purpose of promptly gathering the information and News. In recent times, the research recommends and demands more work on different aspects of social media on greater scale to further enhance the utilization of social media facility as the most accessible method of collecting information and converging the potential media users to transform and impart more knowledge \& skills of finding facts, to verify the reports and information based on most reliable means of journalism. Further study can be carried out on the said footing provided by strong communication through the SNSs and data analysis gathered from alternative means of information \& Social Networking platforms.

\section{References}

1. Friends, fraudsters, and MySpace Top 8: writing community into being on social network sites. https://firstmonday.org/article/view/1418/1336. Date accessed: 2007.

2. Google's orkut puzzles experts. https://www.sfgate.com/business/article/Google-s-Orkutpuzzles-experts-Internet-2633049.php. Date accessed: 29/11/2004.

3. Boczkowski PJ. The mutual shaping of technology and society in videotext newspapers: beyond the diffusion and social shaping perspectives. Information Society. 2004; 20(4), 255-267.

4. Boyd DM, Ellison NB. Social network sites: definition, history, and scholarship. Journal of Computer-Mediated Communication. 2008; 13, 210-230.

5. Raacke J, Bonds-Raacke J. MySpace and Facebook: apply ting the uses and gratifications theory to exploring friend-networking sites. Cyber Psychology \& Behavior. 2008; 11, 169-174.

6. Material virtualities: approaching online textual embodiment. http://www.scirp.org/ (S(czeh2tfqyw2orz553k1w0r45))/reference/ReferencesPapers.aspx?ReferenceID=2152333. Date accessed: 2003. 
7. Friendster lost steam. Is MySpace just a fad? http://www.danah.org/papers/ FriendsterMySpaceEssay.html. Date accessed: 21/03/2006.

8. Business insurance employees' social networking raises employers' liability risk. https://www. bakerlaw.com/Business-Insurance-Getting-Burned-Employees-Social-Networking-RaisesEmployers-Liability-Risk-07-19-2009. Date accessed: 19/07/2009.

9. Social networking and reputational risk in the workplace. https://www.slideshare.net/ opinionwatch/social-networking-and-reputational-risk-in-the-workplace-deloitte-surveyjuly-09. Date accessed: 30/06/2009.

10. Kaplan AM, Heinlein M. Users of the world, unite! The challenges and opportunities of social media. Business Horizons. 2010; 53(1), 59-68.

11. Cassidy J. Me media. The New Yorker. 2006, 50-59.

12. Twitter and the micro-messaging revolution: communication, connections, and immediacy - 140 characters at a time. http://weigend.com/files/teaching/haas/2009/readings/ OReillyTwitterReport200811.pdf. Date accessed: 11/2008.

13. Buzz feed news. https://www.buzzfeednews.com/. Date accessed: 2015.

14. WhatsApp at 1 billion: how can journalists use the chat app for newsgathering? https:// firstdraftnews.org/whatsapp-at-1-billion-how-can-journalists-use-the-chat-app-fornewsgathering/. Date accessed: 2016. 